Opinion

Oopen Access

D) CrossMark

\title{
Coronavirus now-a-days: what does it mean?
}

Keywords: coronavirus, COVID19, EBOLA, SARS

\section{Opinion}

Coronavirus (COVID19) is a major epidemiological problem of Public Health now-a-days due to a particular reason: the sudden explosion of a severe pneumonia, often fatal, which has occurred when epidemiological preventive measures had not yet been put in place, a similar factor characterizing SARS and EBOLA.

What does the disease mean? It is a pneumonia that causes a severe respiratory failure, which may be often fatal, with serologically a diagnostic profile that allows an accurate diagnosis. No effective therapy still exists. How is the cardiovascular system affected?

Undoubtedly there is no direct effect of the virus on the heart, but, however, a pre-existing cardiac impairment, primarily heart failure, is a strongest risk factor affecting negatively the prognosis of those individuals with this viral disease.

\section{Acknowledgments}

None.
Volume I 3 Issue I - 2020

\author{
Aurelio Leone $e^{1,2}$ \\ 'Fellow of the Royal Society for Promotion of Health (FRSPH), \\ UK \\ ${ }^{2}$ Fellow of the American Heart Association (FAHA), USA
}

Correspondence: Aurelio Leone, Fellow of the Royal Society for Promotion of Health (FRSPH), Fellow of the American Heart Association (FAHA), USA, Email reliol@libero.it

Received: February 18, 2020| Published: February 24, 2020

\section{Conflicts of interest}

The authors declare that they have no conflicts of interest.

\section{Funding}

None. 